\title{
Typical nemaline myopathy
}

INSERM

\section{Source}

INSERM. (1999). Orphanet: an online rare disease and orphan drug data base. Typical nemaline myopathy. ORPHA:171436

Typical nemaline myopathy is a moderate neonatal form of nemaline myopathy (NM; see this term) characterized by facial and skeletal muscle weakness and mild respiratory involvement. 